An idiographic analysis of women's accounts of living with mental health conditions in Haredi Jewish communities

\author{
Charlotte Whiteley ${ }^{1,2}$ \\ University of Surrey, United Kingdom \\ Adrian Coyle \\ Kingston University London, United Kingdom \\ Kate Gleeson \\ University of Surrey, United Kingdom
}

${ }^{1}$ Correspondence should be sent to Dr Charlotte Whiteley, Practitioner Doctorate Programme in Psychotherapeutic \& Counselling Psychology, School of Psychology, University of Surrey, Guildford GU2 7XH, Surrey, United Kingdom. Tel: +44 1483 300800. Email: charlotte.whiteley@beh-mht.nhs.uk

${ }^{2}$ Current affiliation: Eating Disorder Service, St Ann’s Hospital, London, United K 


\title{
An idiographic analysis of women's accounts of living with mental health conditions in Haredi Jewish communities
}

\begin{abstract}
This research examines the reported experiences of women who developed mental health conditions while they were members of Haredi Jewish communities. The research focuses on how their communities responded and how these responses affected their self-evaluations and relationships with their communities. A qualitative, idiographic approach was used. Four women were recruited through mental health charities and an online group for former community members. The women were interviewed and transcripts were subjected to Interpretative Phenomenological Analysis. Three cross-case themes were developed: "The negative evaluation of mental health conditions in Haredi communities”, “'Cloak and dagger’: Secrecy and consequences of mental health problems in Haredi communities” and "Going and staying: Mental health experiences and changed relationships with Haredism/Judaism”. The themes are discussed in terms of stigma and the threat posed to Haredi communities’ self-understanding and self-presentation by the women voicing their mental health status within and outside the communities.
\end{abstract}

Keywords: disclosure; Haredi; Jewish; mental health; stigma; women 
An idiographic analysis of women's accounts of living with mental health conditions in Haredi Jewish communities

Although religion can act as a buffer against psychological distress and suicide (for example, Band, Dein, \& Loewenthal, 2011; Spencer, Madden, Purtill, \& Ewing, 2016), stigma may also be attached to mental health conditions within religious communities that can generate prejudice against and marginalisation of those affected. In research on religious communities' understandings of mental health and the implications of these understandings (for example, Baker, 2010; Ciftci, Jones, \& Corrigan, 2013; Trice \& Bjorck, 2006), Jewish “ultra-Orthodox” Haredi communities are under-represented. There is thus a paucity of research-based insight into how community understandings, attitudes and responses have shaped the lived experience of Haredi Jews with mental health conditions.

"Haredi” is derived from a Biblical Hebrew term that denotes someone who “trembles" at the word of God (Greenberg \& Witztum, 2001). Haredism comprises a range of Orthodox Jewish groups in different parts of the world, with different origins and emphases and distinctive customs, prayers and celebrations, each interpreting and expressing its religious values idiosyncratically (for more on the diversity of Orthodox and Haredi communities, see Heilman, 2000; Schnall, 2006). Despite this diversity, some features apply across communities to varying degrees that together make 'Haredism’ a meaningful category.

Haredi communities tend to function as tightly-knit enclaves that prioritise a version of the collective good framed in terms of religious values, community and family. In broad terms, this contrasts with individualistic, industrialised, secular Western societies which valorise personal autonomy, agency and satisfaction. Haredi 
community members' lives are governed by the Torah (the first five books of the Hebrew Bible) and authoritative interpretations of it which determine halachic or religious law and which vary across communities. This law and its interpretations cover a range of aspects of life including family life, diet, dress code, social behaviour, sexual behaviour, study, and engagement with or separation from the secular world (Margolese, 1998). For example, the Hasidic stream within Haredism tends to separate itself from secular society but even here there is a notable exception as the Chabad-Lubavitch Hasidic grouping engages in outreach to unaffiliated Jews (Heilman, 2000).

Marriage and child-bearing are generally considered important religious duties within Haredi communities. Together with religious progression, these are often regarded as community imperatives that must be fulfilled in order for individuals and families to retain an uncompromised membership of the group (Greenberg, Buchbinder, \& Witztum, 2012). Arranged introductions of potential marriage partners or arranged marriages (known as "shidduchim" - "shidduch" in singular form) occur at approximately the age of 20. In some communities, the potential partners may meet only once or twice prior to engagement. Every effort is made to ensure a shidduch occurs for all children. The preference is for a match with someone who is healthy and from a respected family in the community with no evidence of genetic illnesses that could threaten the possibility of producing healthy children.

There is a strong cultural norm about the separation of the sexes and genderspecific roles (Greenberg, Stravynski, \& Bilu 2004). Generally daily life focuses around the study of the Torah for men and child rearing for women, with sizeable families as the norm. Although there are indications of Haredi women working outside the community in some places (Kalekin-Fishman \& Schneider, 2007), this 
remains unusual. The efforts made by many Haredi communities to ensure separation from secular society serve to protect these commitments and structures (Greenberg \& Witztum, 2001). This evokes a strong “in-group”/“out-group” distinction (Margolese, 1998; Ysseldyk, Matheson, \& Anisman, 2010).

Turning to the substantive focus of the present paper, research on the nature and implications of broader social attitudes towards people with mental health difficulties has been commonly located within a stigma framework (for example, Martin, Pescosolido, \& Tuch, 2000; Phelan, Link, Stueve, \& Pescosolido, 2000). A stigmatised individual or group is seen by others as having a negatively evaluated attribute which leads them to be perceived and treated as tainted, defective and socially discredited and to be marginalised and subjected to prejudice and discrimination. Stigma can be seen as defined, enacted and maintained through social interaction within a cultural (and subcultural) system of representation and evaluation (Goffman, 1963; Pescosolido, Martin, Lang, \& Olafsdottir, 2008).

Although some research has highlighted how the cloistered nature of Haredi communities can be supportive to members with mental health difficulties, attitudes towards (people with) mental health conditions among Haredi communities tend to be negative (for example, Heilman \& Witztum, 1997; Loewenthal \& Rogers, 2004). Research has identified community understandings and evaluations of people with mental health conditions that are shared with wider society (Schomerus et al., 2012) and centre on attributions of unpredictability and danger and a desire to maintain social distance from people with mental health conditions. Other reasons for stigmatising responses are more context-specific, as in the example of shidduchim (Cinnirella \& Loewenthal, 1999; Rosen, Greenberg, Schmeidler, \& Shefler, 2008). For example, if Haredi communities attribute biological and genetic causes to mental 
health conditions, this may occasion considerable stigma towards those affected due to the communal importance of marriage and child-bearing (Pirutinsky, Rosen, Shapiro, \& Rosmarin, 2010). There is research indicating that attitudes towards mental health difficulties in Haredi communities are changing and acceptance is evolving and there is research demonstrating the efficacy of value- and culturesensitive support groups and spiritually integrated therapies for Orthodox Jews. Yet progress is slow and there continues to be a multiplicity of issues that create barriers to accessing treatment among community members (Galloway \& Byrne, 2016; Hoffman \& Rossman, 2014; Loewenthal \& Rogers, 2004; Schnall et al., 2014). Given the purposeful self-isolation of many Haredi communities and their deliberate distancing from the secular world, research possibilities are limited, especially when researching sensitive topics (Rier, Schwartzbaum, \& Heller, 2008). It may only be possible to gain access to small numbers of participants. However, this presents the possibility of conducting qualitative research to generate in-depth, contextualised data that convey participants' understandings on their own terms, even if findings can only be transferred beyond their context of origin with tentativeness until a comprehensive picture is established through further studies. This includes idiographic research that focuses on individual meaning and experience and seeks to retain the integrity and coherence of reports from individual participants (Smith, Harré, \& van Langenhove, 1995). This can be achieved through a case study format or by threading individual accounts through an analytic narrative, enabling readers to trace individual participants' experiential journeys. If a level of analysis is desired in terms of cross-case commonalities and differences, a sample is needed that is homogeneous in relation to features that are important to the study. 
While stigma will affect all people with mental health conditions, it is well established that social and cultural factors and unequal power relations mean that men and women will experience mental health conditions differently (World Health Organization, 2000). This may be particularly pertinent within highly gendered Haredi communities. For these reasons, the study described in this paper presents a qualitative, idiographic analysis of experiential accounts provided by four women who developed mental health difficulties while they were members of Haredi communities. In an original contribution to literature on women, mental health and religion, the study examines the women's reported experiences of how their communities responded to their mental health difficulties and how these responses affected their self-evaluations and relationships with their communities.

\section{Method}

\section{Participants}

Participants were sought who were at least 18 years old and had experienced mental health difficulties while living in a Haredi community as community members. Women who had subsequently left their community were eligible to take part. When the research had received a favourable ethical opinion, three women were recruited through mental health-related charities in a Haredi neighbourhood in London. One woman was recruited through an international online group for former members of Haredi communities. This participant currently lives in New York and was formerly a member of the Haredi community there. All participants had received a mental health 
diagnosis from a doctor/psychiatrist (see Table 1 for contextual information on participants; all names are pseudonyms).

[ Insert Table 1 about here ]

\section{Data generation}

Data were generated through semi-structured interviews. The interview schedule began with questions about how participants had experienced the development of their mental health difficulties; who they talked to in their community about their difficulties, if anyone; whether community members had been aware of their difficulties and, if so, how they responded; whether their mental health difficulties changed things for them in their community; whether they were able to seek support from their rabbi, synagogue members or God; whether they sought support outside their community; and how these experiences made them feel about themselves.

Interviews took place at times and locations that were convenient for participants. They were conducted by the first author and lasted between 60 and 90 minutes. In three interviews, the interviewer and the women were physically present to each other. The interview with the participant based in New York was conducted by Skype. All interviews were audio-recorded and transcribed.

\section{Analytic approach}

Transcripts were subjected to Interpretative Phenomenological Analysis (IPA) (Smith, Flowers, \& Larkin, 2009). IPA is an idiographic, phenomenological approach to analysis that is applied to small samples and aims to capture participants' meaningmaking in their personal and social worlds. The analyses produced by IPA are seen as 
the result of a dynamic interaction of participants’ and researchers' subjectivities, oriented towards developing insights into participants’ thinking and lived experience.

The analytic procedure used in this study followed Smith, Flowers and Larkin’s (2009) guidelines for IPA. The first step involved repeated reading of the transcripts which resulted in notes being made on each transcript regarding key phrases and processes that were relevant to the research aims. These notes included summaries of content, connections between different aspects of the transcript, and initial interpretations. Within each transcript, these notes were then condensed to produce initial themes. When this process had been repeated with each transcript, the resulting sets of initial themes were examined to identify recurrent patterns across the transcripts, producing a set of cross-case themes and constituent subthemes. Themes were then ordered in such a way as to produce a logical and coherent research narrative. Across this process, the members of the research team developed and refined themes collaboratively, with discussions centred on the extent to which potential themes and subthemes were grounded in the data and the most effective ways of capturing the essence of participants' accounts of their experiences. The collaborative nature of the analysis reduced the risk of idiosyncratic readings of the data being sustained.

The quality of the analysis was promoted through close alignment with recognised criteria for good qualitative research in this tradition, such as grounding interpretations in examples from the data, conducting credibility checks within the analytic team and optimizing coherence across the study (for example, Yardley, 2000). 


\section{Results}

The three themes that were developed are presented in Table 2. The first theme addresses the negative ways in which participants believed that mental health conditions are evaluated within Haredi communities and the consequences of this for individuals experiencing these conditions. The second theme concerns participants' experiences of secrecy surrounding mental health conditions within the communities and the consequences of disclosure. The third theme addresses the changes that participants believed to have occurred in their relationship with Haredism and with Judaism and religion more generally as a result of how their communities responded to their mental health conditions.

[ Insert Table 2 about here ]

The themes are elaborated, illustrated and interpreted in this section, with higher level interpretations offered in the discussion. In the data excerpts, empty square brackets indicate where material has been omitted; information that appears within square brackets has been added for clarificatory purposes; and ellipsis points (...) indicate a pause in the flow of participants' speech.

\section{The negative evaluation of mental health conditions in Haredi communities}

Throughout the transcripts participants referred to the negative ways in which they felt their mental health condition had been perceived by members of their Haredi community. This theme consists of two subthemes. 
Mental health difficulties as individual failure: Stigmatisation by Haredi communities and self

Repeatedly in the transcripts, there was a sense that in Haredi communities having a known or suspected mental health diagnosis resulted in the person being evaluated negatively and assigned a lower social status than people who were perceived as emotionally and psychologically stable. Miri presented this process as analogous to the way in which a car is "written off" after a crash:

But unfortunately you, people in our community, you hear depression... they are crazy and that's it. You've written them off. Like I'm literally written off if I say that.

Here Miri invoked what she saw as a social representation of the person with depression as definitively having no use or value (“that's it”), as not being a functioning community member or person. Miri's mother had also been diagnosed with depression and, reflecting on her experience of growing up, she felt that the whole family had been stigmatised as a result, saying:

Like we weren’t, weren’t seen as human any more.

Although this subtheme concerns how participants represented their Haredi community as constructing mental health problems as individual failure, here we see that being extended to the individual's family members who are tainted by association. We shall return to this later.

Participants noted how mental health difficulties were communally understood as “failure", specifically moral failure. For example, Hannah said:

When it comes to mental illness in the - in the ultra-Orthodox community...it’s considered a personal moral failing...uh, rather than an illness just like a medical illness where you get a treatment. 
Hannah invoked a comparison between how physical and mental ill-health were communally understood and responded to, with physical illness evoking a treatment response. Her words implied that she favoured an equivalence in how physical and mental ill-health are understood and responded to. However, she represented Haredi communities as viewing mental health problems as "a personal moral failing”, originating and residing within the person and producing a failure to conform to a community moral order. Leaving the community did not entirely deflect the ongoing effects of the community's negative evaluation for Hannah. She explained how a feeling of being “less than” stayed with her:

Um, and I think the idea that people who [ ] have a mental illness or, or diagnosed or take medication are damaged or that, um, are, are morally "less than”...or weak. I think those are some - those are some concepts that even, you know, that are just difficult to let go of. And even when you think you have sometimes, there are - there are some residual kind of effects that are... that are just left there.

Hannah underlined the idea of community evaluations becoming internalised so powerfully that self-stigmatisation is difficult to relinquish. Hannah's reference to people with mental health difficulties being perceived by Haredi communities as “damaged” and “weak” reprised Miri’s “written off” metaphor.

For Chen, moving away from the Haredi community was said to have allowed her to gain access to a different, less individual-focused representational framework for understanding her difficulties. The possibility of not attributing her difficulties exclusively to herself was said to have reduced the potency of her self-stigmatisation: 
[Moving away was] a massive relief and - and acknowledgement that I'm not crazy and it's not just all in my head... For years I've questioned what's wrong with me.

\section{Mental health difficulties as fracturing the moral order}

One specific aspect of how participants said mental health difficulties were understood in Haredi communities was as disturbing the moral order. This has already appeared in quotations from Hannah in the previous subtheme. Other participants spoke about how mental health difficulties were perceived as not conforming to communal expectations of what it means to be a normal Haredi Jew and the prospect of engaging meaningfully with mental health difficulties posed a threat to Haredism in some way.

All participants described their Haredi community as characterised by a rigidly enforced moral order consisting of clear norms and expectations. Chen and Leah compared this to how a cult operates:

Chen: Well I understand the cult basics of keeping people in line is take away all outside communication and feed them whatever you want them to know and, you know, and the rest is irrelevant, so...

Interviewer: And that's what it has felt like, has it?

Chen: What - that I was in a cult? Definitely.

Because if we actually had to talk about mental health issues, they'd have to really look at the causes. Because I feel like the community has got... it’s a cult so there’s a... an attitude of really, “We can’t possibly change anything 
about the way we do things, therefore nothing that we do can be to blame.” (Leah)

Here Leah was referring specifically to the role of sexual abuse in causing mental health difficulties: she attributed her self-diagnosed post-traumatic stress disorder to sexual abuse within her Haredi community. She suggested that the community's norms of operation are treated as immutable and requiring protection from anything that might potentially call for them to be critically examined, such as a consideration of the role played by the community in allowing sexual abuse (and other causes of mental health problems among community members) to occur and continue. Leah saw this as rendering a meaningful, honest understanding of her mental health difficulties as unachievable within her community.

For some participants there was a sense that Haredi communities facilitated and promoted an expectation that everyone ought to be happy. Hannah articulated this most clearly and concisely:

I - I think there was a sense of trying to create, uh, um, trying to create the illusion of utopia - everybody’s happy, everybody’s doing great and that. If you weren’t, um, if - if you don't, then, um, you're a threat to the religion as a whole.

If the community represents itself to itself and others as a context of happiness and well-being and if the community's status depends on this representation appearing credible, it is easy to understand why members' mental health difficulties would be treated as threatening the community's moral order.

Hannah reflected on her experience of community members not engaging with her mental health difficulties and, as she saw it, trying to sustain the communal expectation of members' normality: 
So I do think that there was an effort on their part to try to sweep things under the rug...and try to maintain that sense of normalcy.

Hannah’s reported experience was not unusual: all participants spoke about how mental health difficulties among community members were not considered a legitimate topic for discussion because of a desire to maintain the moral order that informed the representation of happy Haredi Jews.

\section{“Cloak and dagger”: Secrecy and consequences of mental health problems in}

\section{Haredi communities}

Building upon the preceding theme, this theme elaborates the ways in which participants felt the topic of mental health was silenced within their Haredi community and how some felt the need to keep their own difficulties secret. Participants spoke of a pervasive sense of secrecy within Haredi communities whereby problematic issues are not discussed and are kept hidden, arguably in order to maintain the moral order. All participants pointed to the value of marriage as central to Haredi communities and related how disclosing their mental health difficulties had threatened their marriage prospects. These issues constituted the theme's subthemes.

Secrecy and the inexpressibility of mental health difficulties

Participants spoke about how they had been encouraged to keep their personal lives secret and not talk about emotional and psychological difficulties with other community members or with anyone outside their community:

You can’t talk about anything, and everything's bad and a secret and we'll take your, like we’ll take you into a private room and to speak about... 
everything like had to be cloak and dagger if it was... yeah, so it was sort of like a whole, like - like there’s taboo against it, so just, you just don’t talk about it because you don’t want to be - unless you want to be a charity case. (Miri)

The whole - the whole thing of secrecy, you know - you don't share your problems, you don’t, you just don’t, and outside people are - are dangerous, and so no, [I] didn’t have anyone to talk to. [ ] And also because of the rules of, uh, one - a Jew mustn’t inform to the authorities on another Jew, so there were times that social services were in my house and I couldn't say anything. (Chen)

These quotations evoke a sense of secrecy, shame and isolation around the disclosure of psychological difficulties and related phenomena to other community members and outside the community. Miri indicated that disclosure within the community risked having the person with mental health difficulties accorded the low social status of "a charity case”. As Chen noted, disclosure outside the community was unthinkable as non-in-group members were deemed "dangerous" and reporting another Jew to the authorities on account of abuse was deemed a betrayal and an infringement of the communal code. These considerations were said to have prevented her from seeking extra-community help to deal with the difficulties she was experiencing at home. Similar reports from other participants created a sense that these conditions and expectations rendered mental health difficulties inexpressible in most Haredi community contexts and to extra-communal contexts. 
Mental health difficulties as undermining marriage prospects

All participants spoke of the need for community members with mental health difficulties and their families to control the disclosure of information about these difficulties in order to avoid damage to marriage prospects. This was the most explicitly gendered aspect of the data set, with the position of women within participants' Haredi communities underpinning the accounts. All participants drew upon their own experiences, except for Hannah who left her community before marriage became an active issue for her. For example, Leah reported:

And my parents said “Well, oh no, you can’t be on lithium [used to treat major depressive disorder and bipolar disorder] because you will never get a shidduch.” And he's... And he [their rabbi] spoke to my father on the phone and said “She won’t ever get a shidduch if she doesn’t calm down so she needs to be on lithium for that.”

In this discussion, the central concern with obtaining a marriage partner for Leah underlines the overriding importance of marriage and family for Haredi communities. The reported discussion focused on whether treatment with mood-stabilizing medication would risk revealing Leah’s condition to her community and so undermine her chances of securing an arranged marriage or whether an untreated mental health condition would pose a greater risk as it would sabotage her marriage prospects. Leah's individual well-being was not the core concern in itself within this reported interaction. Instead its importance was mediated through communal value priorities or the communal moral order. Her role in the shidduchim process was reported as one of presenting herself as choose-able. 
In elaborating the ways in which potential marriage partners and their families are closely scrutinized by match-makers in the shidduchim process, Chen underlined the risk posed by any indication of (mental) health problems:

You can't be on, on any medication or... or have anything that's... that would potentially...um, because the match-makers do such a thorough background search. [ ] If they knew that a person had, you know... was taking any medication or had a history of mental illness in the family, then they wouldn't be able to do anything for the family.

When Chen said "for the family" here, it was not clear whether she meant that the match-maker would be unable to find a potential partner for the person with mental health difficulties or more generally for members of that whole family. It is likely to have been the latter as this was explicitly voiced by both Hannah and Miri:

There is definitely is a sense that if you are, um, that you kind of become labelled [ ] and if you were labelled, then you would have difficulty finding a marriage partner later on, um, and that everyone in your family would be tainted.... by that, by that label. (Hannah)

Like, because my mother had depression, the - the guy [potential marriage partner for Miri’s sister] wanted a letter from the - my mum’s doctor saying that my sister wouldn't get it as well and that it wasn't hereditary. That - like that's how bad it is. It's like, if the person - "If there’s depression in that family, don't marry into that family.” It's - it’s ridiculous. (Miri) These reflections suggested that there is a communal representation of mental health problems as genetically-based and so the occurrence of these problems in one family member taints other family members and undermines their marriage prospects. The 
extent to which mental health problems may sabotage a person's marriage prospects was indicated by Miri who said:

Then it came to, um, suggesting people for me to marry. Thirty-three year-old pedophile - like this guy, who like everyone is known, is like, "Yeah, sure go with him.”

Here she reported that her prospects had been so seriously impaired that someone whose prospects were also seriously impaired was considered a potential match, in this case a man who was known to the community as a pedophile. It was as if an equivalence in social status and stigma was assumed between mental health difficulties and pedophilia. Miri's account of this occasion provides another indication of marriage as an absolute priority within the community value system. The psychological well-being of the women was treated as secondary to the social wellbeing that would be achieved through marriage.

\section{Going and staying: Mental health experiences and changed relationships with}

\section{Haredism/Judaism}

Across the interviews, all participants talked about how their relationship and engagement with Haredism and Judaism had changed as a result of how their religious community had responded to their mental health difficulties. They discussed how their experiences had led them to reflect critically on Haredi communal outlooks and value systems. Two participants decided to leave their Haredi community and Judaism. The other two participants reported engaging with Haredism in a new way after critical reflection. These different implications are presented as separate subthemes. 


\section{A considered exit from Haredism}

As a result of the responses they had received to their mental health difficulties from their Haredi community, Chen and Hannah said they lost faith in their religion and moved away from their religious community. Both participants provided explanatory accounts of this outcome, constructing their exits as considered, reasoned responses. Chen felt that she began to lose faith when her prayers were not answered and when she lost trust in the rabbis who had not supported her:

Erm and yeah, I used to - I used to pray, daven [Yiddish term meaning to recite prescribed prayers] really hard. And yeah, you know, he’s [God] not answering me and what did I do wrong that he hates us? And... I think I was losing my faith already back then. I definitely lost faith in the rabbis.

Hannah, who now defined herself as non-religious, reflected in more general terms on her decision to depart from Judaism and religion:

Um religion is supposed to essentially give - give a person a purpose... um, make, you know, make you happy, um, you know, make you feel fulfilled. And - and if it, if it’s, if it doesn’t, then you're essentially proving it wrong. [ ] I began to see the religion as very, um, very rigid... and very unaccepting of - of people's differences.

Here Hannah conceptualised the purpose of religion in individualised terms - as giving a framework of meaning, happiness and fulfilment to the person - and suggested that if religion does not deliver these outcomes, it is invalid. She then applied these functional criteria to Haredism specifically and found it wanting on account of its perceived rigidity and its difficulty in accepting difference (in mental health status in this case) within its communities. 


\section{A reconsidered and revised engagement with Haredism}

In contrast, Leah and Miri continued to value their religious tradition and found new ways of engaging with it. Leah explicitly rejected the option of departure on the grounds that she perceived the benefits of her religious tradition as outweighing the problems that she had discussed:

Yeah. I th-... I think if I haven’t been through all the things I've been through, I don’t know I would've stopped to critically look at what's going on. Um, what it has brought me to is a... a more modern... Some people would just reject religion altogether. Um I find religion a comfort. I think the sense of community, the rituals, and the... there's so much richness and... and complexity... And there's plenty of other ways to do it. So what I've done is become much more interested in... I call it honest orthodoxy.

Among the benefits that Leah ascribed to her religious engagement was "the sense of community”, even though earlier she described the community as cult-like and attributed her self-diagnosed post-traumatic stress disorder to sexual abuse that she had experienced within her community. It seemed that, for Leah, the benefits of community life and the "richness" and "complexity" that she found in Haredism and her Haredi community outweighed the limitations and problems associated with this tradition and context. In the above quotation, she stressed that her continued involvement with her religious tradition was not an unthinking engagement. She emphasised that she has undertaken critical evaluation and has developed an approach to Haredi life of which she claims ownership to the extent that she named it herself, saying “I call it honest orthodoxy”. In this excerpt, Leah crafted a picture of herself as active in her religious thinking, perhaps seeking to deflect any interpretation of her decision to remain within her community as indicating passive compliance. 
Miri reported having moved to the outskirts of her community both geographically and psychologically. Like Leah, she described having had to develop a personally workable way of religious life but emphasised her ongoing commitment to her Jewishness:

So I realised that yeah, I do have to make my own but I still - I love being Jewish. I - I - I keep kosher. I - I um I’m proud to be Jewish. This emphasis on being Jewish rather than being a Haredi Jew may represent a shift to a more inclusive and accommodating identity category in which she more comfortably fits.

\section{Discussion}

The four women who took part in the study presented thoroughly contextualised accounts of living with mental health difficulties in Haredi communities. This reflects the study's commitment to the role of social location in shaping experience and the community emphasis in the interview schedule.

Some of what the participants described echoed themes in the literature on stigma in general and mental health stigma in particular. These concerned the social representation of mental health problems as individual failure, the management of discrediting information, and the negative implications for social worth that follow from the occupation of a socially discredited position, with the implications for marriage prospects presented as a vivid example. Furthermore, instances of dehumanisation were observed in the data. For example, Miri observed that, due to her mother's diagnosis with depression, it was as if her family had not been seen "as 
human any more” by the community. Together with infra-humanisation, this has been recognised as a feature of stigma and prejudice (for example, see Leyens, Demoulin, Vaes, Gaunt, \& Paladino, 2007; Marcu \& Chryssochoou, 2005). Goffman’s (1963) notion of "courtesy stigma" or stigma-through-association was also exemplified in the findings. This occurred in participants' accounts of how the attribution of a genetic basis to mental health problems by community members legitimised the extension of stigma from the woman with the mental health condition to her family. Additionally, factors associated with the internalisation of stigma (where people with mental health conditions apply negative societal evaluations of mental health status to themselves) have been subjected to research attention (for example, see Livingston \& Boyd, 2010). The women in the present study reflected upon this issue in different ways. For example, while Hannah recognised her ongoing self-stigmatisation, even after having left her Haredi community, Chen felt that she had been able to challenge her internalisation of stigma through encountering alternative, non-psychologically corrosive ways of understanding her mental health history.

Link and Phelan’s (2001) emphasis on power positions, status loss, stereotyping and separation in stigma is especially pertinent to the women's accounts here and their representation of Haredi communities as characterised by a communitydefining set of norms and expectations that are rigorously enforced and treated as immutable. Two women used this to construct Haredism as a closed, non-porous social system (“it’s a cult”): this is what makes processes of stigma distinctive in Haredi communities, even though communities vary in porousness. Participants attended particularly to norms about shidduchim and about communities' representation of themselves to themselves and others as normal and happy which, in their accounts, were part of a communal moral order. The latter appeared to have the 
power to place in question the in-group membership of those whose voicing of their mental health status infringed the norm and threatened the representation, especially if that voicing happened outside the community. Participants spoke of this as a significant threat to Haredism's self-understanding and self-presentation which links to the secrecy about mental health status that was reported.

The participants' experience of moral surveillance may also be considered in relation to their being positioned primarily as child-bearers. Where communities emphasise child-rearing, control over reproduction to ensure valued genetic outcomes may be managed through prevention of marriage, segregation of sexes and close surveillance of women. This is not particular to religious communities: it resonates with Warren’s (1987) accounts of the experiences of women diagnosed with schizophrenia in the USA in the 1950s.

The position that the women spoke of having occupied within Haredi communities by virtue of their mental health status could be seen as a liminal one (Murphy, Scheer, Murphy, \& Mack, 1988; Thomassen, 2009). Their non-conformity with and/or the challenges they posed to important norms within the community’s moral order located them outside the prototypical ideal for community members. Their liminal position may have facilitated the departure of two women from their Haredi community and may have underpinned the rationales for departure that they offered concerning a loss of religious belief and a reconceptualisation of religion as rigid, unaccepting of difference and unable to provide purpose and fulfilment. It is worth noting that one woman who remained communally engaged in a revised way (Miri) reported having adopted a liminal position in geographical and identity terms in that she moved to the outskirts of her community and saw herself as Jewish rather than a Haredi Jew. 
Although the present research has offered insights into and interpretations of the communal experiences of the four women, it is not feasible to develop confident recommendations from the study for addressing the difficulties reported by the women within Haredi communities. Developing generalisable findings from representative samples is not the aim of idiographic research but questions remain about whether and how much these women's reported experiences typify the experiences of women with mental health histories in Haredi communities. Three women were London-based and one woman lived in New York; their experiences may at least partly have been shaped by differences in how Haredi communities are structured and function in those different settings as well as by diversity across Haredi communities in any one setting. It is also important to acknowledge that the women were all in their twenties: older women may have had different experiences that reflect shifts in community understandings, norms and structures over time. Further research is needed with women and men who have experienced mental health difficulties within Haredi communities in order to expand the picture created through the present study and to identify experiential commonalities with increasing confidence. For now, though, some provisional observations can be offered on the basis of aspects of the findings that relate to the structures and norms of Haredi communities.

There is a substantial body of research on how actual contact, imaginary contact, education and campaigning can reduce stigmatising attitudes towards and self-stigmatisation among people with mental health conditions (Corrigan, Kosyluk, \& Rüsch, 2013; Lamboy \& Saias, 2013; Stathi, Tsantila, \& Crisp, 2012). The implementation of these strategies within Haredi contexts is complicated by many communities' insularity and community-defining norms. Nonetheless, this work 
needs to be undertaken because the current study and previous research have pointed to how stigma around mental health problems can be a barrier to help-seeking within and outside the communities (Loewenthal \& Rogers, 2004; Rosen et al., 2008). Moreover, as noted earlier, there are indications that mental health knowledge has been gradually increasing and stigma decreasing over time in some Orthodox Jewish communities, including Haredi contexts.

Some resources have been developed by Haredi mental health professionals and within Haredi communities for responding constructively to the mental health needs of community members (for example, Hoffman \& Rossman, 2014; Lightman \& Shor, 2002). Other resources have been developed that are designed to engage with a range of Jewish service users, including people from Haredi communities (for example, see Rosmarin, Pargament, Pirutinsky, \& Mahoney, 2010). The key feature of this work has been its development by and/or with credible community members (individuals and organisations). Rabbis can be particularly credible advocates for educational and service provision initiatives in their communities and can implement constructive approaches to mental health problems within their pastoral role, although a workable synthesis needs to be achieved with fundamental religious requirements. An example of this can be found in Greenberg and Shefler's (2008) study which found that rabbis of Haredi people who were experiencing religious-related symptoms of Obsessive Compulsive Disorder adopted a lenient attitude towards halachic laws when it came to recovery from this condition and recommended treatment that was in line with cognitive behavioural therapy. A useful framework for facilitating multidisciplinary collaboration to confront issues such as mental health problems in religious communities is offered by the Clergy Outreach and Professional Engagement (COPE) model (Milstein, Manierre, Susman, \& Bruce, 2008). This sees 
psychologists, clergy and other professionals working collaboratively and sharing their knowledge and expertise to promote the wellbeing of religious community members. Implementing it with Haredi communities would require sensitive and open engagement with community commitments and norms. Yet, the potential benefits for people with mental health difficulties within these communities call for a constructive, diligent approach to meeting the challenges. 


\section{References}

Baker, M. (2010). How do service-users experience their local faith community and their mental health staff team? A UK perspective. Journal of Psychology and Christianity, 29(3), 240-251.

Band, M., Dein, S., \& Loewenthal, K. (2011). Religiosity, coping, and suicidality within the religious Zionist community of Israel: A thematic qualitative analysis. Mental Health, Religion \& Culture, 14(10), 1031-1047.

Ciftci, A., Jones, N., \& Corrigan, P. W. (2013). Mental health stigma in the Muslim community. Journal of Muslim Mental Health, 7(1), 17-32.

Cinnirella, M., \& Loewenthal, K. M. (1999). Religious and ethnic group influences on beliefs about mental illness: A qualitative interview study. British Journal of Medical Psychology, 72(4), 505-524.

Corrigan, P. W., Kosyluk, K. A., \& Rüsch, N. (2013). Reducing self-stigma by coming out proud. American Journal of Public Health, 103(5), 794-800.

Galloway, A., \& Byrne, A. (2016). “There is something about working together”: Improving talking therapies provision to the Orthodox Jewish communities of north London. Clinical Psychology Forum, 284, 38-42.

Goffman, E. (1963). Stigma: Notes on the management of spoiled identity. Englewood Cliffs, NJ: Prentice Hall.

Greenberg, D., Buchbinder, J. T., \& Witztum, E. (2012). Arranged matches and 
mental illness: Therapists’ dilemmas. Psychiatry, 75(4), 342-354.

Greenberg, D., \& Shefler, G. (2008). Ultra-orthodox rabbinic responses to religious Obsessive-Compulsive Disorder. The Israel Journal of Psychiatry and Related Sciences, 45(3), 183-192.

Greenberg, D., Stravynski, A., \& Bilu, Y. (2004). Social phobia in ultra-orthodox Jewish males: Culture-bound syndrome or virtue? Mental Health, Religion \& Culture, 7(4), 289-305.

Greenberg, D., \& Witztum, E. (2001). Sanity and sanctity: Mental health work among the ultra-orthodox in Jerusalem. New Haven, CT: Yale University Press.

Haslam, N., Loughnan, S., Kashima, Y., \& Bain, P. (2009). Attributing and denying humanness to others. European Review of Social Psychology, 19(1), 55-85.

Heilman, S. (2000). Defenders of the faith: Inside ultra-Orthodox Jewry. Berkeley, CA: University of California Press.

Heilman, S. C., \& Witztum, E. (1997). Value-sensitive therapy: Learning from ultraorthodox patients. American Journal of Psychotherapy, 51(4), 522-541.

Hoffman, S., \& Rossman, L. (2014). Psychological treatment and the Haredi community: Issues and case studies. New York: Golden Sky.

Kalekin-Fishman, D., \& Schneider, K. (2007). Radicals in spite of themselves: UltraOrthodox women working outside the Haredi community. Rotterdam: Sense Publishers.

Lamboy, B., \& Saias, T. (2013). Réduire la stigmatization des personnes souffrant de 
troubles psychiques par une campagne de communication? Une synthèse de la littérature. Annales Medico-Psychologiques, 171(2), 77-82.

Leyens, J.-P., Demoulin, S., Vaes, J., Gaunt, R., \& Paladino, M. P. (2007). Infrahumanization: The wall of group differences. Social Issues \& Policy Review, 1(1), 139-172.

Lightman, E. S., \& Shor, R. (2002). Askanim: Informal helpers and cultural brokers as a bridge to secular helpers for the Ultra-Orthodox Jewish communities of Israel and Canada. Families in Society: The Journal of Contemporary Human Services, 83(3), 315-324.

Link, B. G., \& Phelan, J. C. (2001). Conceptualizing stigma. Annual Review of Sociology, 27, 363-385.

Livingston J. D., \& Boyd J. E. (2010). Correlates and consequences of internalized stigma for people living with mental illness: A systematic review and metaanalysis. Social Science \& Medicine, 71(12), 2150-2161.

Loewenthal, K. M., \& Rogers, M. B. (2004). Culture-sensitive counselling, psychotherapy and support groups in the Orthodox-Jewish community: How they work and how they are experienced. International Journal of Social Psychiatry, 50(3), 227-240.

Marcu, A., \& Chryssochoou, X. (2005). Exclusion of ethnic groups from the realm of humanity: Prejudice against the Gypsies in Britain and in Romania. Psicología Política, 30, 41-56.

Margolese, H. C. (1998). Engaging in psychotherapy with the orthodox Jew: A 
critical review. American Journal of Psychotherapy, 52(1), 37-53.

Martin, J. K., Pescosolido, B. A., \& Tuch, S. A. (2000). Of fear and loathing: The role of disturbing behavior, labels, and causal attributions in shaping public attitudes toward persons with mental illness. Journal of Health and Social Behavior, 41(2), 208-233.

Milstein, G., Manierre, A., Susman, V. L., \& Bruce, M. L. (2008). Implementation of a program to improve the continuity of mental health care through clergy outreach and professional engagement (COPE). Professional Psychology: Research and Practice, 39(2), 218-228.

Murphy, R. F., Scheer, J., Murphy, Y., \& Mack, R. (1988). Physical disability and social liminality: A study in the rituals of adversity. Social Science \& Medicine, 26(2), 235-242.

Pescosolido, B. A., Martin, J. K., Lang, A., \& Olafsdottir, S. (2008). Rethinking theoretical approaches to stigma: A Framework Integrating Normative Influences on Stigma (FINIS). Social Science \& Medicine, 67(3), 431-440.

Phelan, J. C., Link, B. G., Stueve, A., \& Pescosolido, B. A. (2000). Public conceptions of mental illness in 1950 and 1996: What is mental illness and is it to be feared? Journal of Health and Social Behavior, 41(2), 188-207.

Pirutinsky, S., Rosen, D., Shapiro, R. L., \& Rosmarin, D. H. (2010). Do medical models of mental illness relate to increased or decreased stigmatization of mental illness among Orthodox Jews? Journal of Nervous and Mental Diseases, 198(7), 508-512. 
Richard, A. (2013). Discussion of Alison Feit’s ‘Modesty from cats, sexual morality from doves: Orthodox Jewry’s silence in the face of sexual misconduct’. International Journal of Psychoanalytic Self Psychology, 8(2), 173-178.

Rier, D. A., Schwartzbaum, A., \& Heller, C. (2008). Methodological issues in studying an insular, traditional population: A women’s health survey among Israeli Haredi (ultra-orthodox) Jews. Women \& Health, 48(4), 363-381.

Rosen, D. D., Greenberg, D., Schmeidler, J., \& Shefler, G. (2008). Stigma of mental illness, religious change, and explanatory models of mental illness among Jewish patients at a mental-health clinic in North Jerusalem. Mental Health, Religion \& Culture, 11(2), 193-209.

Rosmarin, D. H., Pargament, K. I., Pirutinsky, S., \& Mahoney, A. (2010). A randomized controlled evaluation of a spiritually integrated treatment for subclinical anxiety in the Jewish community, delivered via the internet. Journal of Anxiety Disorders, 24(7), 799-808.

Rüsch, N., Angermeyer, M. C., \& Corrigan, P. W. (2005). Mental illness stigma: Concepts, consequences, and initiatives to reduce stigma. European Psychiatry, 20(8), 529-539.

Schnall, E. (2006). Multicultural counseling and the Orthodox Jew. Journal of Counseling \& Development, 84(3), 276-282.

Schnall, E., Kalkstein, S., Gottesman, A., Feinberg, K., Schaeffer, C. B., \& Feinberg, S. S. (2014). Barriers to mental health care: A 25-year follow-up study of the Orthodox Jewish community. Journal of Multicultural Counseling and Development, 42(3), 161-173. 
Schomerus, G., Schwahn, C. C., Holzinger, A. A., Corrigan, P. W., Grabe, H. J., Carta, M. G., \& Angermeyer, M. C. (2012). Evolution of public attitudes about mental illness: A systematic review and meta-analysis. Acta Psychiatrica Scandinavica, 125(6), 440-452.

Smith, J. A., Flowers, P., \& Larkin, M. (2009)., Interpretative phenomenological analysis: Theory, method and research. London: SAGE.

Smith, J. A., Harré, R., \& van Langenhove, L. (1995). Idiography and the case study. In J. A. Smith, R. Harré, \& L. van Langenhove (Eds.), Rethinking psychology (pp. 59-69). London: SAGE.

Spencer, N., Madden, G., Purtill, C., \& Ewing, J. (2016). Religion and well-being: Assessing the evidence. London: Theos.

Stathi, S., Tsantila, K., \& Crisp, R. J. (2012). Imagining intergroup contact can combat mental health stigma by reducing anxiety, avoidance and negative stereotyping. Journal of Social Psychology, 152(6), 746-757.

Thomassen, B. (2009). The uses and meaning of liminality. International Political Anthropology, 2(1), 5-27.

Trice, P. D., \& Bjorck, J. P. (2006). Pentecostal perspectives on causes and cures of depression. Professional Psychology: Research and Practice, 37(3), 283-294.

Trounson, J. S., Critchley, C., \& Pfeifer, J. E. (2015). Australian attitudes toward asylum seekers: Roles of dehumanization and social dominance theory. Social Behavior \& Personality: An International Journal, 43(10), 1641-1655.

Warren, C. A. B. (1987). Madwives: Schizophrenic women in the 1950s. New 
Brunswick, NJ: Rutgers University Press.

World Health Organization (2000). Women's mental health: An evidence-based review. Geneva: World Health Organization.

Yardley, L. (2000). Dilemmas in qualitative health research. Psychology and Health, 15(2), 215-228.

Ysseldyk, R., Matheson, K., \& Anisman, H. (2010). Religiosity as identity: Toward an understanding of religion from a social identity perspective. Personality and Social Psychology Review, 14(1), 60-71. 
Table 1: Description of participants

\begin{tabular}{|c|c|c|c|}
\hline $\begin{array}{l}\text { Participant's } \\
\text { pseudonym }\end{array}$ & $\begin{array}{l}\text { Age at time } \\
\text { of interview }\end{array}$ & Mental health condition & Religious affiliation \\
\hline Chen & 26 & $\begin{array}{l}\text { Depression (diagnosed at age } \\
\text { 16) }\end{array}$ & $\begin{array}{l}\text { Jewish - raised in } \\
\text { Haredi community }\end{array}$ \\
\hline Hannah & 27 & $\begin{array}{l}\text { Depression and Attention } \\
\text { Deficit Hyperactivity } \\
\text { Disorder (diagnosed at age } \\
\text { 19) }\end{array}$ & $\begin{array}{l}\text { Non-religious - raised } \\
\text { in Haredi community }\end{array}$ \\
\hline Leah & 29 & $\begin{array}{l}\text { Postnatal depression (official } \\
\text { diagnosis in early adulthood) } \\
\text { and Post-Traumatic Stress } \\
\text { Disorder (self-diagnosed) }\end{array}$ & $\begin{array}{l}\text { Haredi Jew - resides } \\
\text { in Haredi community }\end{array}$ \\
\hline Miri & 25 & $\begin{array}{l}\text { Depression and Borderline } \\
\text { Personality Disorder } \\
\text { (diagnosed in teenage years) }\end{array}$ & $\begin{array}{l}\text { Traditional Jewish - } \\
\text { resides on the } \\
\text { outskirts of a Haredi } \\
\text { community }\end{array}$ \\
\hline
\end{tabular}


Table 2: Themes and subthemes

\begin{tabular}{|c|c|}
\hline Themes & Subthemes \\
\hline $\begin{array}{l}\text { The negative evaluation of mental health } \\
\text { conditions in Haredi communities }\end{array}$ & $\begin{array}{l}\text { - Mental health difficulties as individual } \\
\text { failure: Stigmatisation by Haredi } \\
\text { communities and self } \\
\text { - Mental health difficulties as fracturing } \\
\text { the moral order }\end{array}$ \\
\hline $\begin{array}{l}\text { “Cloak and dagger”: Secrecy and } \\
\text { consequences of mental health problems } \\
\text { in Haredi communities }\end{array}$ & $\begin{array}{l}\text { - Secrecy and the inexpressibility of } \\
\text { mental health difficulties } \\
\text { - Mental health difficulties as } \\
\text { undermining marriage prospects }\end{array}$ \\
\hline $\begin{array}{l}\text { Going and staying: Mental health } \\
\text { experiences and changed relationships } \\
\text { with Haredism/Judaism }\end{array}$ & $\begin{array}{l}\text { - A considered exit from Haredism } \\
\text { - A reconsidered and revised engagement } \\
\text { with Haredism }\end{array}$ \\
\hline
\end{tabular}

